\title{
Cooling temperature and heat transfer coefficients in cylindrical heat exchangers
}

\author{
Enrique Torres Tamayo ${ }^{1}$, José W. Morales ${ }^{2}$, Mauro D. Albarracín ${ }^{1}$, Héctor L. Laurencioํㅜㄹ Israel P. \\ Pachacama ${ }^{1}$, Brayan I. Guacapiña ${ }^{1}$, Wilson M. Román ${ }^{3}$ \\ ${ }^{1}$ Cotopaxi Technical University, Latacunga City, ECUADOR \\ ${ }^{2}$ Cotopaxi Higher Technological Institute, Latacunga City, ECUADOR \\ ${ }^{3}$ Armed Forces University, Latacunga City, ECUADOR
}

Received: May 30, 2021. Revised: November 15, 2021. Accepted: December 22, 2021. Published: December 28, 2021.

\begin{abstract}
The parameters behavior that characterize the process was carried out through an experimental investigation to obtain the cooling temperature, heat transfer coefficients and the heat flow in mineral coolers. The values of water temperature, water flow and mineral temperature were recorded at the inlet and outlet of the cylindrical cooler. Experiments were carried out with five values of the mass flow, keeping the cylinder revolutions constant. The calculation procedure for the system was obtained, in the mineral coolers the heat transfer by conduction, convection and evaporation predominates as a function of the cooling zone. A reduction in temperature is shown with increasing length, the lowest temperature values were obtained for a mass flow of $8 \mathrm{~kg} / \mathrm{s}$. The mineral outlet temperature should not exceed $200{ }^{\circ} \mathrm{C}$, therefore it is recommended to work with the mass flow less than $10 \mathrm{~kg} / \mathrm{s}$ that guarantees the cooling process.
\end{abstract}

Keywords - cooling temperature, heat transfer coefficients, cylindrical heat exchangers.

\section{INTRODUCTION}

AFTER the mineral reduction process to obtain nickel, the cooling process is carried out in rotating cylinders. Through heat transfer processes the mineral must be cooled from $750^{\circ} \mathrm{C}$ to $200^{\circ} \mathrm{C}$, the temperature required to process the mineral. The desired values are not achieved and the water and energy consumption of the process is higher than expected in this equipment.

The desired temperature values are not reached, the consumption of water and thermal energy is higher than expected. Although work has been developed focused on reducing these energy indicators, no results are reported regarding the heat transfer processes that allow obtaining adequate values.

A scientific investigation must be supported by a theoretical and empirical investigation. In the development of the research, different works and studies were consulted, the bibliographic review was directed in two fundamental lines: the information related to the theoretical-methodological approach and the works that have been carried out on the subject of heat exchange in rotating cylinders in recent years.

In the research [1] the mathematical model and the main equations of the cooling process in rotating cylinders are proposed. The modelling is based on the approach of energy balance equations, from which a system of differential equations is obtained, which are complemented by others that establish the relationship between the coefficients and physical parameters. The results obtained are theoretical because the validation of the equations is not achieved. The experimental analysis that allows obtaining the theoreticalexperimental model, using scaling techniques and experiments design is not carried out. A behavior of the mineral exit temperature in parabolic form differs from the results obtained in the present investigation. The insufficient knowledge about the relationship that exists between the behavior of the mineral temperature and the main parameters and variables in the cooling process, motivated the development of the research.

The analysis of heat transfer in cylinders has been studied by various researchers [2]. The author analyzes the average heat transfer characteristics for a $16 \mathrm{~mm}$ diameter cross flow cylinder in a vertical pipe, for which uses two types of flows: single-phase and multi component. Research shows that water heat transfer coefficients are approximately four times the values of oil, furthermore it is found that introducing air as second phase with water has very little effect on the rate of heat transfer. In another important work [3], the behavior pattern of heat transfer in multiphase flows depends on the flow rates, the physical properties of the fluids and the pipe inclination.

Pavlovich's article [4] takes into account the effect of cylinder rotation and its influence on heat transfer. The author analyzes the problem of two-dimensional heat transfer from a rotating cylinder, investigates the incidence of incompressible cross flow under an isothermal boundary condition. The study is based on the numerical solution of the conservation equations of mass, momentum and energy as a function of the Reynolds number. The investigation revealed that the rate of heat transfer decreases with increasing rotational speed of the cylinder. The increase in the Prandtl number resulted in an appreciable increase in the mean Nusselt number.

In the research developed by Blanka [5], the heat transfer equations are obtained as a function of the Reynolds number for horizontal cylinders. The authors validate the results using the numerical and analytical method. The maximum value of the convective heat transfer coefficient appears near the connection of the walls, where the intensity of the turbulence is highest and the largest vortices are created. Other investigations dedicated to the analysis of turbulence intensity and the local disturbance generated behind the cylinder are also important $[6,7]$. Numerical simulation techniques to increase the heat transfer rate of a cylinder in cross flow are carried out through numerical and experimental investigations [8]. 
Another interesting work where experimental and numerical investigations are carried out to study the heat transfer coefficient around a cylindrical surface is developed by Akram [9]. The research analyzed the positioning of the cylinder at a vertical, horizontal and inclined $45^{\circ}$ angle with respect to the free air stream and variable Reynolds numbers.

The local heat transfer coefficients around the cylinder are investigated as a function of the measured heat flux value and the temperature differences between the cylinder surface and the air stream. The values obtained are similar to other results reported in the literature [10]

The research developed by Mohammed [11] performs the prediction of the heat transfer coefficient of steam condensation inside a horizontal pipe, the influence of heat flow and temperature on the heat transfer coefficient is also analyzed. The results show that the heat transfer coefficient decreases with increasing heat flux, while it increases with steam saturation temperature. Kumar [12] analyzes the heat transfer process during nucleate boiling, very important to increase the efficiency of the equipment, which helps to reduce the use of fossil fuels, the author obtains the dependence of the heat transfer coefficient as a function of heat flow for different fluids, including water as the working fluid.

Davletshin [13] performs optical measurements showing the behavior of the heat transfer coefficient in the separation region. The heat transfer coefficients in plate exchangers are obtained in the research developed by Tamayo [14]. They allow the calculation of the Nusselt number and the overall heat transfer coefficient for ammonia liquor cooling process. In the research [15], it get the mathematical modeling of the coal activation process in order to predict the behavior of the gas and coal temperature distribution inside a rotary cylindrical kiln. Is obtained the model groups a non-linear differential equations system, the equations to determine the temperature of the cylinder inner wall and the heat transfer coefficients.

In previous works, phenomenological models are presented to describe the behavior of the process variables throughout the cylinder length. However, the rotary cylindrical cooler are still empirically designed due to the lack of an appropriate model of heat transfer that characterizes the behavior of the variables in the process [16]. Another important publication is the one developed by Christopher Provatidis [17], where is established the teaching the fixed spinning top using four alternative formulations.

The objective of this research was to establish a model to predict the cooling temperature and heat transfer coefficients in cylindrical heat exchangers.

\section{METHOD DEVELOPMENT}

\section{A. Cooling process analysis}

To determine the heat transfer coefficients during mineral cooling, an experimental installation was used as shown in figure 1 .

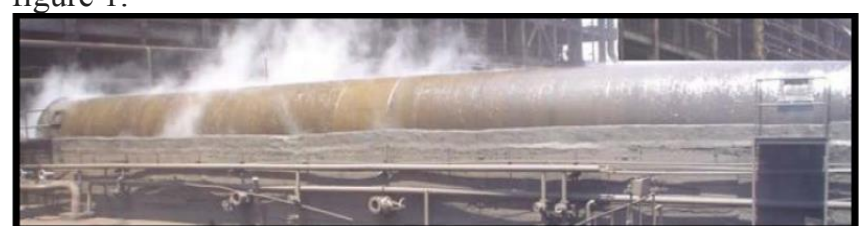

Figure 1. Experimental installation of the mineral cooling process
Figure 2 shows the inside of the mineral cooler, the inside elements allow the mineral remotion to facilitate the heat exchange process.

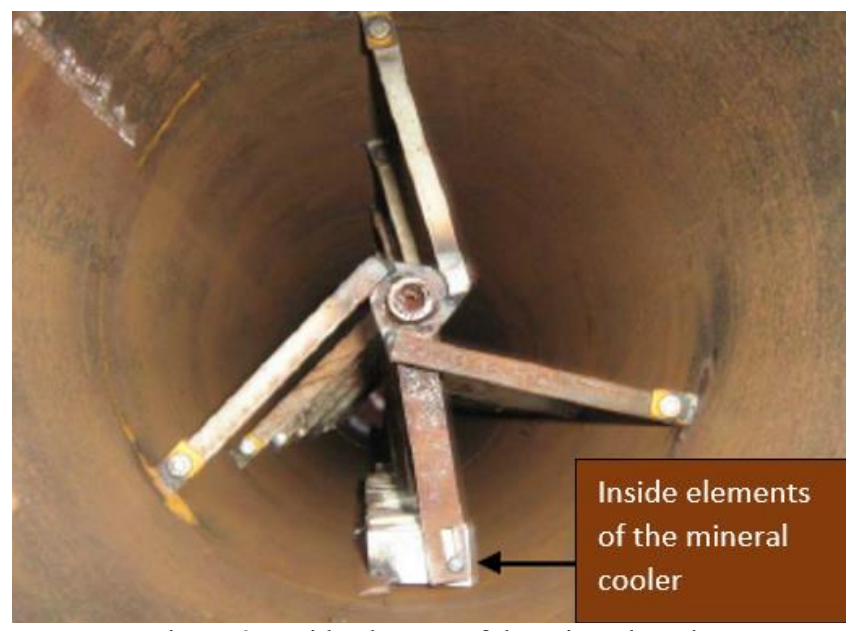

Figure 2. Inside element of the mineral cooler

Two modes of heat transmission are present in this process (conduction and convection). The mineral discharged into the cooler, at a temperature between $350^{\circ} \mathrm{C}$ and $400^{\circ} \mathrm{C}$, transfers heat by conduction and convection to the inner surface of the cylinder, with conduction transfer predominant due to the solid-solid contact. Heat is also transferred by convection due to the presence of combustion gases that accompany the mineral inside the cylinder. Then, from the outer surface heat is exchanged by convection with the water that is under atmospheric conditions, giving rise to its progressive heating to values between $40^{\circ} \mathrm{C}$ and $55^{\circ} \mathrm{C}$, forming a small film of water; subsequently, the heat transfer from water to air by convection and evaporation occurs (Figure 3 ).

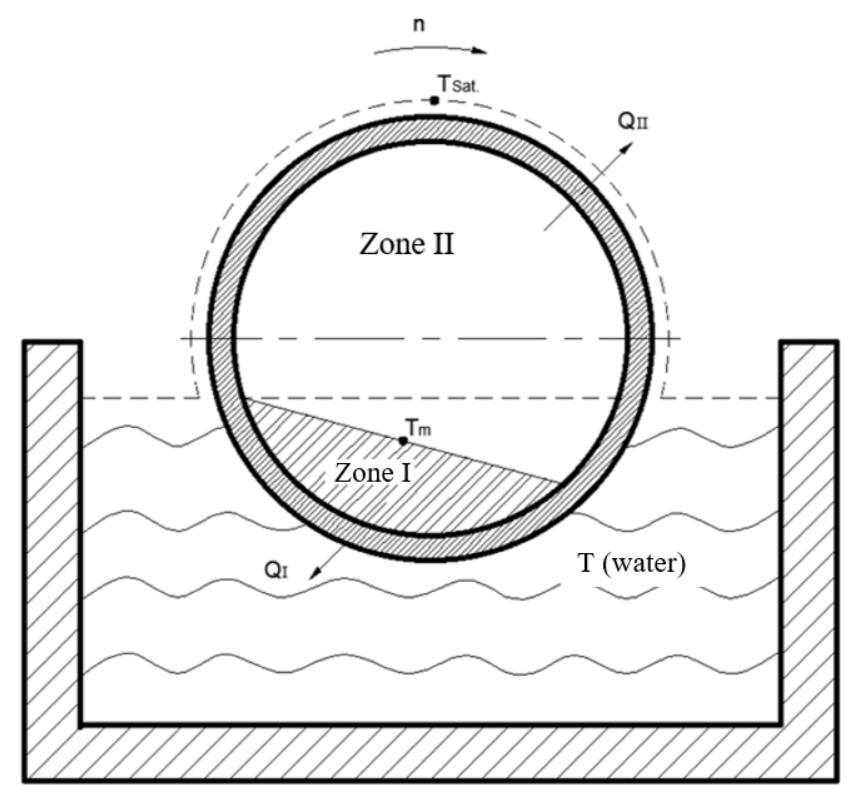

Figure 3. Heat transfer modes during mineral cooling.

Due to the complexity of the heat transfer process that takes place in the cooling of the mineral inside the cylinder, the total heat transfer area is divided into two zones with different characteristics: the first zone is related to the heat exchange between the mineral and the cooling water present in the pool and the second, the thermal exchange takes place 
between the hot air inside the cylinder and the water that evaporates on the outside surface. These zones are analyzed below:

\section{B. Heat transfer process for the zone I}

The heat transfer process in this area is between the mineral surface $\left(T_{m}\right)$ and the water in the pool $\left(T_{f}\right)$, the heat is transferred by conduction from the mineral mass and the thickness of the cooler, later by forced convection between the outer surface of the cooler and the fluid present in the pool [17]. The resistance circuit is as follows:

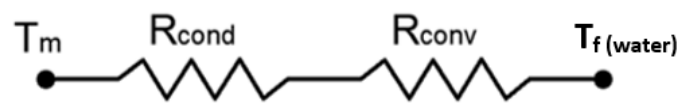

Figure 4 . The resistance circuit of the mineral cooling process

The total thermal resistance is determined as the sum of each resistances and the heat flow in the length of the cooler is obtained by equation 1 .

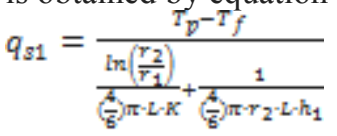

The cross-sectional area of the mineral is determined by the following equation.

$$
A=0,667 \cdot r_{1}^{2} \cdot \beta^{a}
$$

The angle $\beta$ takes into account the area covered by the mineral as shown in figure 5 .

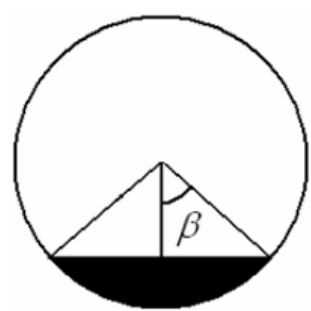

Figure 5. Representation of the filling angle $\beta$

The filling angle is determined by the following equation $\beta=\sqrt[3]{\frac{a}{2 \Psi_{1}^{2} \rho \cdot v_{m}^{2}}}$

A solid granulate is considered a porous medium, a material with a solid structure that contains interconnected spaces [16]. In natural porous media, the distribution and shape of the pores is irregular, while they are uniform in synthetic media (insulating and building materials). The mineral speed inside the cylinder can be determined by knowing the cylinder inclination angle, the internal diameter of the cooler and the rotation speed. This equation is obtained experimentally.

\section{$V_{m}=5,78 \cdot D_{1} \cdot \varphi \cdot n$}

(4)

To determine the convection heat transfer coefficient by outside the cooler, it is taken into account the empirical correlation due to Churchil and Bernstein [16]. The author develops the subject related to the general theory of heat transfer, the physical laws and principles related to heat transmission are conceptualized. In this work, different practical situations are exposed where heat transfer phenomena are linked with the equipment existing in the processes. The Churchill and Bernstein equation, shown in equation 5, covers the entire range of Reynolds and Prandts number $[16,18]$

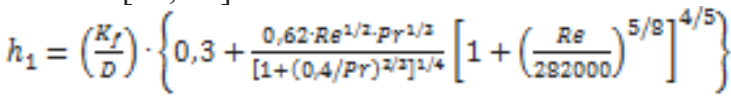

The value of the Reynolds number is determined by equation 6 . The value depends on the cylinder diameter, the speed of the cooling water and the kinematic coefficient of viscosity.

$R_{e D}=\frac{V_{a} \cdot D_{2}}{D_{a}}$

\section{Heat transfer process for the zone II}

In this area the heat transfer process is directed from the inner surface of the cylinder to the water film that is on the outer surface not submerged in the pool, for this the heat flow is transferred by conduction in the thickness of the cooler and subsequently by nucleated boiling of the water film. The heat flux transferred by the mineral along the length of the cooler, considering the inner surface of the cooler that is not covered, is obtained by equation 7 .

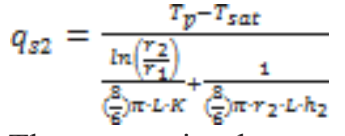

The convection heat transfer coefficient $\left(h_{2}\right)$, is determined by equation 8 .

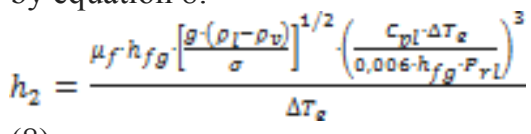

(8)

The total heat flux transferred from the cylinder surface is determined by Equation 9, adding the heat flux transferred in both zones.

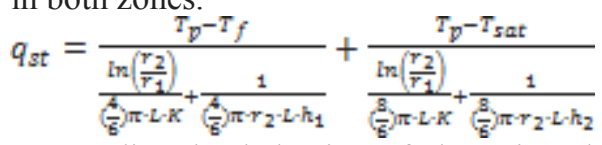

To predict the behavior of the mineral temperature as a function of the length, an energy balance is carried out (equation 10).

$T_{\mathrm{mx}}=T_{\mathrm{mi}}-\frac{\pi D_{1} \varphi_{\mathrm{st}}}{\mathrm{W} \cdot \mathrm{C}_{\mathrm{m}}} \times x$

The previous equations make up the calculation method to obtain the mineral outlet temperature as a function of the cylinder length. The heat transfer processes have been divided into two zones to differentiate the heat flow towards the water inside the pool and the evaporation that occurs in the non-submerged part. The model parameters are obtained in an experimental installation, placing instruments that allow the variables to be recorded.

\section{Procedure for the solution of the physical-mathematical model}

The experimental installation consists of the following equipment and accessories: cylindrical cooler, water storage pool, electric motors, instrumentation and control of the parameters. According to the analysis of the cooling process as object of physical-mathematical modeling and the developed theoretical model, the outlet temperature of the mineral in the cooler depends fundamentally on the following factors.

- Mineral Mass flow at the inlet of the cooler. Experiments were performed with five mass flow values: $0,125 \mathrm{~kg} / \mathrm{s} ; 0,139 \mathrm{~kg} / \mathrm{s} ; 0,153 \mathrm{~kg} / \mathrm{s} ; 0,167$ $\mathrm{kg} / \mathrm{s}$ and $0,181 \mathrm{~kg} / \mathrm{s}$.

- The mineral temperature at the inlet of the cooler is $325^{\circ} \mathrm{C}$. 
- The water inlet temperature in the pool is $26^{\circ} \mathrm{C}$ and $76{ }^{\circ} \mathrm{C}$ at the outlet. The saturation temperature of the water is $100{ }^{\circ} \mathrm{C}$ and the ambient air is $28^{\circ} \mathrm{C}$.

- The cooler revolutions number is 6.12 r.p.m

- The cylinder surface temperature was measured at 10 points with sensors placed along its length.

- The cylinder diameter is $1.5 \mathrm{~m}$ and the length is $12 \mathrm{~m}$.

The mineral from the deposits is subjected to a drying and grinding process, until obtaining a granulometry of 0.074 $\mathrm{mm}$ and moisture content of $4.5 \%$. The mineral reduction occurs in the multiple hearth furnaces. When the cylinder is fed, the experimentation begins. Due to the automation existing in the process, the values of the parameters are recorded by each instrument and the signal is sent to the process control.

The identification of the mathematical model plays a fundamental role because it establishes its adequacy to the object studied; hence an identification algorithm is applied by comparing the experimental results with those of the model. The identification of the mathematical model is carried out by comparing the mineral outlet temperature obtained experimentally with values from the model.

In the model identification is necessary to use an iterative procedure starting from the reference state, and the Runge Kutta fourth order method that takes into account the behavior of the derivative in four points of each interval. This method, like part of the iterative process is used to solve the theoretical model and to find the values of mineral outlet temperature [19].

The number of experiments was determined from the application of a multifactorial design. In agreement with the determined levels of each variable. The confirmation of the validity of the experimental results with the theoretical model is developed through the relative error, that is, the difference between the experimental value "Xexp" of the temperature and the theoretical value "Xteo" obtained by the model for the same conditions of the experiment. The relative error is calculated by the following expression:

$$
E_{p}=\left|\frac{X_{\mathrm{gxp}}-X_{\mathrm{th}}}{x_{\mathrm{Exp}}}\right|=100 \%
$$

The average relative error is expressed for:

$$
E=\sum_{i=1}^{n}\left|\frac{x_{\mathbb{E x p}}-x_{\mathrm{th}}}{x_{\mathrm{Exp}}}\right| \cdot \frac{10036}{n}
$$

The following factors influence the comparative errors between the experimental and theoretical temperature values:

- Characteristics of the measuring instruments

- Disturbances that may occur in the measured variables

- The experimental values are averages of the measurements

- Possible appreciation errors during measurements

\section{RESULTS AND DISCUSSION}

Figure 6 shows the behavior of the convection heat transfer coefficient and the heat flux as a function of the Reynolds number in zone 1. An increase in the heat flux transferred is observed due to the presence of heat transfer by conduction between the material and the walls. Increasing the speed of the water in the pool does not affect the heat flow significantly. The maximum values obtained are below $3,7 \cdot 10^{2} \mathrm{~W} / \mathrm{m}^{2} \mathrm{~K}$. The maximum value of heat flux transferred in zone 1 is $8 \cdot 10^{6} \mathrm{~W}$, this increase it is related to the mineral mass flow and the cooler rotational speed.

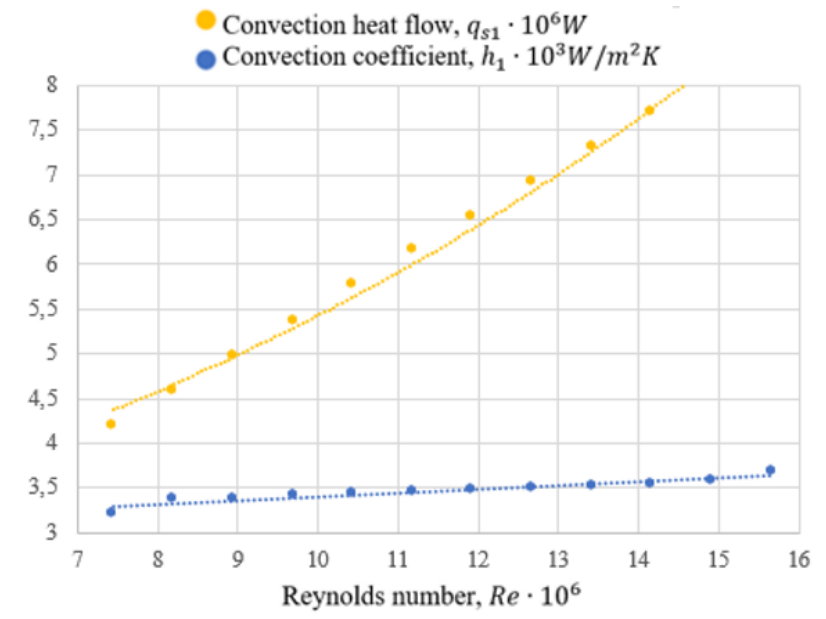

Figure 6. Behavior of the heat transfer coefficient and heat flux as a function of the Reynolds number in zone I.

Figure 7 shows the behavior of the heat flow as a function of the evaporation temperature in zone II. The evaporation process occurs due to the water film boiling on the outside of the cooler that is not submerged. The heat drag towards the ambient air causes the cooling of the mineral that is inside the cylinder. The maximum value of the heat flux dissipated in zone II was obtained for rotational speed values of 5 r.p.m, where results $11,3 \cdot 10^{5} \mathrm{~W} / \mathrm{m}^{2}$ were obtained. With the increase in the temperature of the cooler surface, the transferred heat flux increases, the maximum values were obtained for a surface temperature of $134{ }^{\circ} \mathrm{C}$.

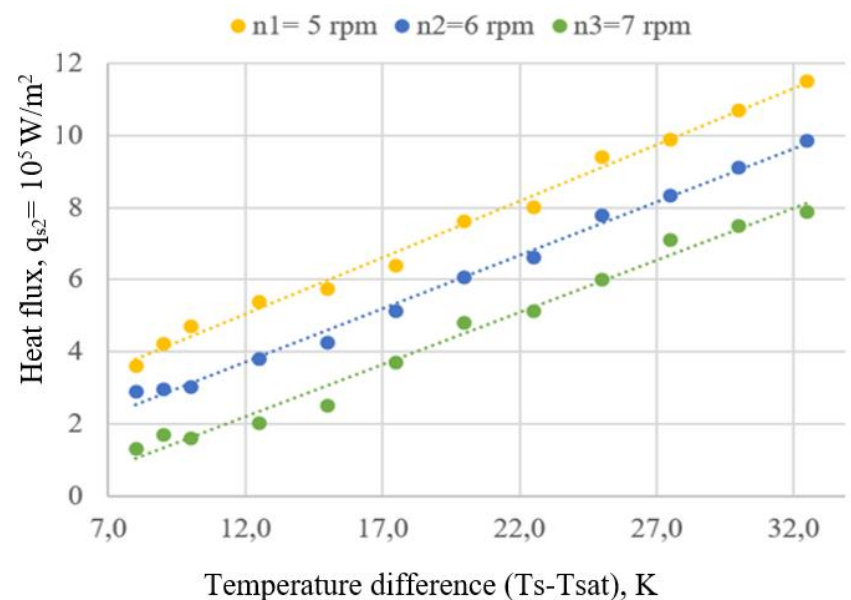

Figure 7. Behavior of the heat flow as a function of the evaporation temperature in zone II.

The results of the mineral outlet temperature as a function of the cooler length can be observed in figures 8 and 9. A reduction in temperature is shown with increasing length, the lowest temperature values were obtained for a mass flow of $8 \mathrm{~kg} / \mathrm{s}$. The process establishes that the outlet temperature of the mineral must not exceed $200{ }^{\circ} \mathrm{C}$. The cooler operation must be with a mass flow lower than $10 \mathrm{~kg} / \mathrm{s}$ that guarantees the demands of the subsequent process. 


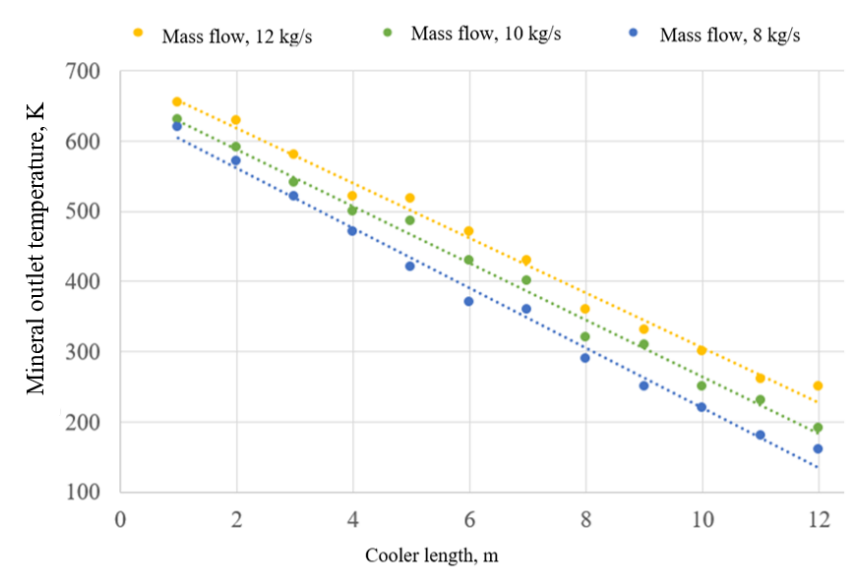

Figure 8. Behavior of the heat flow as a function of the boiling temperature in zone II.

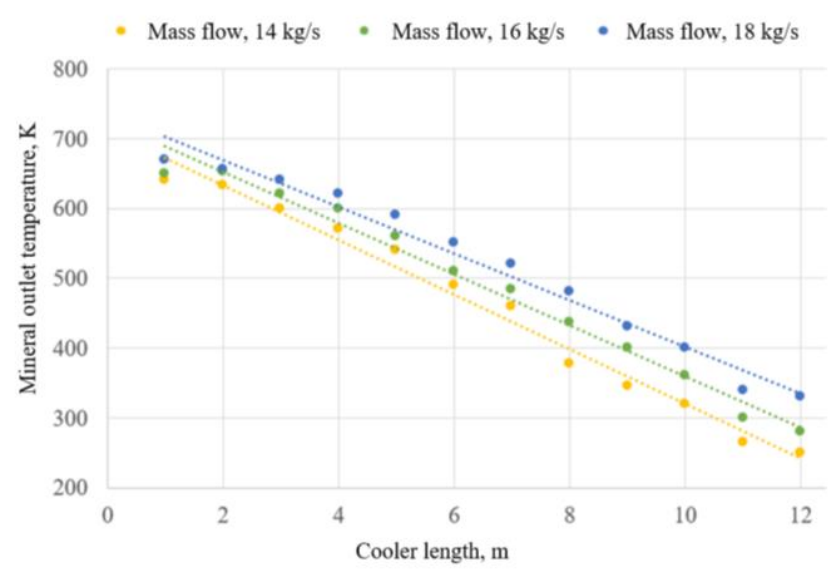

Figure 9. Behavior of the heat flow as a function of the boiling temperature in zone II.

To compare the experimental results of the mineral outlet temperature in the cooler with the theoretical results (equation 10), a multifactorial design was used. The variables considered in the design are: mineral mass flow at the inlet of the cooler, the mineral temperature at the inlet of the cooler, the water inlet temperature in the pool, the cooler revolutions number and the water speed in the pool. The number of experiments carried out was 20, varying the mineral mass flow at the inlet of the cooler in four levels and the water speed in the pool in five levels. At each of the levels, three replications were made.

Table (1) shows the values of the temperature variation along the cylinder length, the results were recorded for a length variation of two meters. The average relative error, in all cases, is below $6.9 \%$. This confirms the validity of the results obtained from the theoretical modeling of the mineral cooling process.

Table 1. Temperature values as a function of the cylinder length.

\begin{tabular}{|l|l|l|l|}
\hline $\mathrm{L}(\mathrm{m})$ & $T_{\text {mo exp }}$ & $T_{\text {mo theorical }}$ & $\begin{array}{l}\text { Relative } \\
\text { error }\end{array}$ \\
\hline 2 & $590^{\circ} \mathrm{C}$ & $582^{\circ} \mathrm{C}$ & $1,4 \%$ \\
\hline 4 & $500^{\circ} \mathrm{C}$ & $487^{\circ} \mathrm{C}$ & $2,6 \%$ \\
\hline 6 & $420^{\circ} \mathrm{C}$ & $427^{\circ} \mathrm{C}$ & $1,7 \%$ \\
\hline 8 & $335^{\circ} \mathrm{C}$ & $322^{\circ} \mathrm{C}$ & $3,9 \%$ \\
\hline 10 & $247^{\circ} \mathrm{C}$ & $264^{\circ} \mathrm{C}$ & $6,9 \%$ \\
\hline 12 & $187^{\circ} \mathrm{C}$ & $193{ }^{\circ} \mathrm{C}$ & $3,2 \%$ \\
\hline
\end{tabular}

\section{CONCLUSIONS}

- The mathematical model that characterizes the heat transfer during the mineral cooling process in a rotary cylindrical was established. The heat transfer processes have been divided into two zones to differentiate the heat flow towards the water inside the pool and the evaporation that occurs in the non-submerged part.

- The experiments were carried out using a multifactorial design. The average relative error, in all cases, is below $6.9 \%$. This confirms the validity of the results obtained from the theoretical modeling of the mineral cooling process.

- An increase in the heat flux transferred is observed due to the presence of heat transfer by conduction between the material and the walls. Increasing the speed of the water in the pool does not affect the heat flow significantly. The maximum values obtained are below $3.7 \times 10^{2} \mathrm{~W} / \mathrm{m}^{2} \mathrm{~K}$. The maximum value of heat flux transferred in zone 1 is $8 \cdot 10^{6} \mathrm{~W}$, this increase it is related to the mineral mass flow and the cooler rotational speed.

- The mineral outlet temperature decreases with increasing length, the lowest temperature values were obtained for a mineral mass flow of $8 \mathrm{~kg} / \mathrm{s}$. The process establishes that the outlet temperature of the mineral must not exceed $200{ }^{\circ} \mathrm{C}$. The cooler operation must be with a mineral mass flow lower than $10 \mathrm{~kg} / \mathrm{s}$ that guarantees the demands of the subsequent process.

\section{Nomenclature:}

$T_{m}$ - Mineral temperature, $\mathrm{K}$

$T_{f}$ - Water temperature, $\mathrm{K}$

$R_{\text {cond }}$ - Cylinder conduction resistance, $\mathrm{K} / \mathrm{W}$

$R_{\text {conv }}$ - Convection resistance from outer surface to water, $\mathrm{K} / \mathrm{W}$

$T_{p}$ - Wall temperature inside the cylinder, $\mathrm{K}$

$r_{1,2}-$ Cylinder inner and outer radius, $m$

$L-$ Cylinder length, $\mathrm{m}$

$K$ - Thermal conductivity of the material in the cooler, $\mathrm{W} / \mathrm{mK}$

$h_{1}$ - Convection heat transfer coefficient, $\mathrm{W} / \mathrm{m}^{2} \mathrm{~K}$

$\beta$ - Angle that takes into account the area occupied by the mineral, degrees

m- Mineral mass flow, $\mathrm{kg} / \mathrm{s}$

$V_{m}$ - Mineral velocity inside the cylinder, $\mathrm{m} / \mathrm{s}$

$\rho$ - Mineral density, $\mathrm{kg} / \mathrm{m}^{3}$

$\varphi$ - Cylinder slope angle, degrees

$D_{1}$ - Cooler inner diameter, $\mathrm{m}$

$\mathrm{n}-$ Cylinder rotation speed, $\mathrm{rpm}$

$K_{f}$ - Water thermal conductivity in the pool, W/mK

D - Cooler outer diameter, $\mathrm{m}$

$P_{F}$ - Prandtl number, dimensionless

Re - Reynolds number, dimensionless

$V_{a}$ - Cooling water speed, $\mathrm{m} / \mathrm{s}$

$v_{\alpha}-$ Viscosity kinematic coefficient of cooling water; $\mathrm{m}^{2} / \mathrm{s}$.

$T_{\text {sat }}$ - Water saturation temperature; K.

$h_{2}$ - Convection heat transfer coefficient in zone II; W/ $/ \mathrm{m}^{2} \mathrm{~K}$.

$\mu_{f}$-Dynamic viscosity; N.s $/ \mathrm{m}^{2}$.

$h_{f g}$ - Vaporization heat; $\mathrm{kJ} / \mathrm{kg}$. 
$g$ - Gravity constant; $\mathrm{m} / \mathrm{s}^{2}$.

$\rho_{l} \cdot \rho_{V}$ - Density of liquid and vapor respectively; $\mathrm{kg} / \mathrm{m}^{3}$.

$\sigma$ - Surface strain; N/m.

$C_{\mathrm{pl}}$ Liquid specific heat; $\mathrm{J} / \mathrm{kg} \mathrm{K}$.

$\Delta T_{e^{-}}$Temperature difference between outer surface and saturation temperature; $\mathrm{K}$.

$P_{\text {rl }}$ - Prandtl number

$q_{s t}$ - Heat flow transferred from the cylinder Surface, W

$q_{s t}$ - Heat flux transferred from the cylinder surface, $\mathrm{W} / \mathrm{m}^{2}$

$C_{m}$ - Mineral specific heat, $\mathrm{J} / \mathrm{kg} \mathrm{K}$

$T_{m i}$ - Inlet mineral temperature, $\mathrm{K}$

$T_{m x}$ - Mineral temperature as a function of the length, K

\section{REFERENCES}

[1]Gongora, E. et al (2007). Mathematical model for an industrial cooling process of solids in rotating cylinders. Journal of Energetic, Vol. XXVIII (2), pp. 15-25. ISSN 1815-5901.

[2]Hamad F (2017). Heat Transfer from a Cylinder in Cross-Flow of Single and Multiphase Flows. International Journal of Mechanical, Aerospace, Industrial, Mechatronic and Manufacturing Engineering Vol. 11 (3), pp. 370-374.

[3]Hamad, F.; Dlir A. \& Ganesan, P. (2014). Study of kerosene-water two-phase flow characteristics in vertical and inclined pipes. Journal of Chem Eng, Vol 92, pp. 905-917.

[4]Pavlovich, N. \& Jakgrit S. (2009). Numerical simulation of flow and forced convection heat transfer in crossflow of incompressible fluid over two rotating circular cylinders. Journal of Sci. Technol. Vol 17(1), pp 87-104.

[5]Blanka, S. et al (2018). Forced convection and heat transfer around a bounded cylinder. MATEC Web of Conferences 157, $02045 \quad$ (2018). https://doi.org/10.1051/matecconf/201815702045.

[6]Huang C. K., Y. J. Cheng, Y. P. Kang, (2007). Combined effect of grid turbulence and unsteady wake on convective heat transfer around a heated cylinder. Int. Comm. Heat Mass Transfer 34, 1091 1100.

[7]Quintino A. (2012). Experimental analysis of the heat transfer coefficient enhancement for a heated cylinder in cross-flow downstream of a grid flow perturbation. App. Thermal Eng. 35, 55-59

[8]Billah M. et al. (2011). Numerical analysis of fluid flow due to mixed convection in a lid-driven cavity having a heated circular hollow cylinder. Int. Com. Heat Mass Trans. 38, 1093-1103.

[9]Akram W. \& Hassan W (2013). Forced Convection Heat Transfer around Heated Inclined Cylinder. International Journal of Computer Applications. 73 (8), 04-11.

[10] Sarkar S., A. Dalal, G. Biswas, (2011)“'Unsteady wake dynamics and heat transfer in forced and mixed convection past a circular cylinder in cross flow for high Prandtl numbers'Journal of Fluid Mechanics,Vol.54,pp. 3536-3551.

[11] Mohammed K., Muna K. \& Louay M. (2013). Predicting of steam condensation heat transfer coefficient in horizontal flattened tube. Journal of
Engineering and Sustainable Development. 24 (6), 115-126.

[12]Kumar A. et al (2021). Performance of heat transfer mechanism in nucleate pool boiling -a relative approach of contribution to various heat transfer components. Journal of Thermal Engineering. 24 (1), 1-11. https://doi.org/ 10.1016/ j.csite.2020.100827.

[13] Davletshin I. (2020). Data on distribution of heat transfer coefficient and profiles of velocity and turbulent characteristics behind a rib in pulsating flows. Journal of Data in Brief 33 (2020) 106485. https://doi.org/10.1016/j.dib.2020.106485.

[14] Tamayo E. et al (2016). Overall heat transfer coefficients, pressure drop and power demand in plate heat exchangers during the ammonia liquor cooling process. International Journal of Mechanics, vol. 12, pp. 08-13. ISSN: 19984448.

[15] Oliva C. et al (2019). Mathematical modeling of the coal activation process in rotary cylindrical kiln. International Journal of Mechanics, vol. 13, pp. 15-20. ISSN: 19984448.

[16] Nield D. A. \& Bejan A [2013]. Convection in Porous Media. 4th Edition. Springer. London. $\mathrm{p}$ 778. ISBN 978-1-4614-5541-7. https://www.springer.com/gp/book/978148999822 4

[17] Christopher G. Provatidis, "Teaching the Fixed Spinning Top Using Four Alternative Formulations", WSEAS Transactions on Advances in Engineering Education, vol. 18, pp. 80-95, 2021

[18] Incropera, F. P. \& David P. W. Fundamentals of Heat and Mass. Transfer, John Wiley \& Sons. 2011. New York. U.S.A. p. 886. ISBN 13 9780470-50197-9.

[19] Torres T. E., et al (2017). Energy consumption and simulation of pneumatic conveying lateritic mineral in dense and fluid phase. International Journal of Mechanics, vol. 11, pp. 12-17. ISSN: 19984448.

Creative Commons Attribution License 4.0 (Attribution 4.0 International, CC BY 4.0)

This article is published under the terms of the Creative Commons Attribution License 4.0 https://creativecommons.org/licenses/by/4.0/deed.en_US 